\title{
Reduction of exogenous ketones depends upon NADPH generated photosynthetically in cells of the cyanobacterium Synechococcus PCC 7942
}

\author{
Rio Yamanaka ${ }^{1 *}$, Kaoru Nakamura ${ }^{2}$ and Akio Murakami $^{3}$
}

\begin{abstract}
Effective utilization of photosynthetic microorganisms as potential biocatalysts is favorable for the production of useful biomaterials and the reduction of atmospheric $\mathrm{CO}_{2}$. For example, biocatalytic transformations are used in the synthesis of optically active alcohols. We previously found that ketone reduction in cells of the cyanobacterium Synechococcus PCC 7942 is highly enantioselective and remarkably enhanced under light illumination. In this study, the mechanism of lightenhanced ketone reduction was investigated in detail using several inhibitors of photosynthetic electron transport and of enzymes of the Calvin cycle. It is demonstrated that light intensity and photosynthesis inhibitors significantly affect the ketone reduction activity in Synechococcus. This indicates that the reduction correlates well with photosynthetic activity. Moreover, ketone reduction in Synechococcus specifically depends upon NADPH and not NADH. These results also suggest that cyanobacteria have the potential to be utilized as biocatalytic systems for direct usage of light energy in various applications such as syntheses of useful compounds and remediation of environmental pollutants.
\end{abstract}

Keywords: biocatalysis, cyanobacteria, ketone reduction, light energy, NADPH, photosynthesis

\section{Introduction}

Most chlorophyll-containing organisms are photoautotrophic and manufacture various organic compounds from inorganic carbon in the form of $\mathrm{CO}_{2}$ using solar light energy. All other organisms except for chemosynthetic bacteria are heterotrophic and ultimately depend upon photoautotrophic organisms to provide their energy and nutrients (Anemaet et al. 2010). Oxygen-evolving photoautotrophic organisms, plants, algae, and cyanobacteria have significantly influenced the global environment and carbon cycle on Earth. Improved utilization of such photoautotrophic organisms will be essential in preventing acceleration of a rise in anthropogenic $\mathrm{CO}_{2}$, which is believed to cause global warming and ocean acidification (Zabochnicka-świątek 2010). In particular, aquatic microalgae and cyanobacteria are among the most promising candidates in efforts to reduce atmospheric $\mathrm{CO}_{2}$ because they have higher photosynthetic activity and proliferate faster than terrestrial plants (Kurano et al. 1998). For this

\footnotetext{
* Correspondence: rioy@himeji-du.ac.jp

${ }^{1}$ Faculty of Pharmaceutical Science, Himeji-Dokkyo University, 7-2-1 Kami-

Ohno, Himeji, Hyogo 670-8524, Japan

Full list of author information is available at the end of the article
}

purpose, large-scale mass-culture of microalgae and cyanobacteria has been accomplished using either outdoor open pond processes or enclosed bioreactor systems (Takano et al. 1992, Ugwu et al. 2005, Kumar et al. 2010).

Optically active alcohols are useful for organic syntheses of chemical catalysts, liquid crystals, flavors, agrochemicals, and drugs (Goldberg et al. 2007a, b, Moore et al. 2007, Huisman et al. 2010). There have been many reports on the synthesis of optically active alcohols using chemical and biological catalysts (Nakamura et al. 2003, Carey et al. 2006, Matsuda et al. 2009). Most of the reports on biocatalytic transformations have been focused on non-photosynthetic and heterotrophic microorganisms or their isolated enzymes (Nakamura et al. 2003, Matsuda et al. 2009). In these biocatalytic reactions, organic compounds, such as sugars produced by photosynthetic organisms, are used as crucial energy sources. These biocatalytic reactions indirectly and ultimately depend upon solar light energy. In terms of energy acquisition efficiency, photoautotrophic organisms appear to be the most effective biocatalytic agents (Nakamura 2007). In fact, there have been several reports on asymmetric reduction using photoautotrophs such as 
microalgae (Noma and Asakawa 1992, Kuramoto et al. 1999, Nakamura et al. 2000, Utsukihara et al. 2004, Shimoda et al. 2004, Itoh et al. 2005, Utsukihara et al. 2006, Takemura et al. 2009), plant cultured-cells (Kojima et al. 2009), and germinated plants (Matsuo et al. 2008, Takeda et al. 2011). Enzymatic systems isolated from a microalga were used in combination with NADPH (nicotinamide adenine dinucleotide phosphate) to perform a biotransformation such as biocatalytic reduction (Shimoda and Hirata 2000).

To develop the use of autotrophic biocatalysts for reduction of exogenous substances, mechanistic studies on biocatalytic reduction reactions are necessary. Particularly, the effect of light on the reaction should be investigated in detail because light is needed in order to take advantage of the catalytic power of autotrophic biocatalysts. We previously reported that light illumination enhances the chemical and optical yields in the cyanobacteria-catalyzed reduction of exogenous ketones (Nakamura and Yamanaka $2002 a, b)$. To investigate the effect of light on chemical yields of cyanobacterial ketone reduction precisely, an acetophenone derivative, $\alpha, \alpha, \alpha$-trifluoroacetophenone (TFA) was selected as the substrate for bioconversion because the ketone was easily reduced by the cyanobacterium and the optical yields of the product alcohol were unchanged by light conditions. Havel et al. (2007) reported that cyanobacterial ketone reduction was enhanced by light or glucose. Takemura et al. (2009) indicated that enantioselectivities of the reduction by a cyanobacterium could be influenced by deletion of genes from an endogenous dehydrogenase that requires coenzymes such as NADH/ NADPH, which provide reducing power. Moreover, Hölsch et al. identified the enzyme involved in the cyanobacterial reduction reaction and the enzymes are NADPHdependent (Hölsch et al. 2008, Hölsch and Weuster-Botz, 2010). We propose that the reducing power generated by increasing concentrations of NADPH through photosynthetic electron transport can be used in the reduction of exogenous ketones to yield useful alcohols. In cyanobacteria, the concentration of NADPH under illuminated conditions is approximately 6.5-fold higher than that of NADH (Tamoi et al. 2005).

In this report, we investigate the process and mechanism of reduction of exogenous ketones in cyanobacteria (Synechococcus PCC 7942) from the point view of reducing power, in terms of endogenous NADPH produced through photosynthesis. Here, we show that NADPH produced through photosynthesis is definitely used in the reduction of exogenous ketones in cyanobacteria.

\section{Materials and methods}

Organism and culture

Synechococcus elongatus PCC 7942 (Synechococcus) was obtained from the Pasteur Culture Collection of
Cyanobacteria (PCC) of the Institut Pasteur, France. The cyanobacterium was grown in BG-11 medium (Rippka 1988) under continuous illumination (13.4 $\mu \mathrm{mol}$ photons $\mathrm{m}^{-2} \cdot \mathrm{s}^{-1}$ ) provided by fluorescent lamps (daylight type, $20 \mathrm{~W}$; Toshiba) at $25^{\circ} \mathrm{C}$ on a rotary shaker. Cell density was estimated by the turbidity at $720 \mathrm{~nm}$ of the cell suspension using a spectrophotometer (U-3210; Hitachi, Japan).

\section{Chemicals}

TFA ( $\alpha, \alpha, \alpha$-trifluoroacetophenone), PF (2', 3', 4', 5', 6'pentafluoroacetophenone), and IAM (iodoacetamide) were purchased from Tokyo Chemical Industry (Tokyo, Japan). DCMU (3-(3,4-dichlorophenyl)-1,1-dimethylurea), D,L-glyceraldehyde, 5'-AMP, NADPH, and $\mathrm{NADH}$ were purchased from Nacalai Tesque (Kyoto, Japan). DBMIB (2,5-dibromo-3-methyl-6-isopropyl-pbenzoquinone) and IAA (iodoacetic acid) were purchased from Sigma-Aldrich (St. Louis, MO, USA). All of the reagents used were of analytical grade.

\section{Gas chromatography}

The chemical yields for ketone reduction were determined by GC (gas chromatography) analyses using a Shimadzu gas chromatography system GC-14B with CR6A equipped with a chiral GC-column (CP-cyclodextrin-B-2,3,6-M-19 [CPCD]; $25 \mathrm{~m}$; He $2 \mathrm{~mL} / \mathrm{min})$. Naphthalene was used as an internal standard.

\section{Assay for cellular reduction of ketones}

The ketones (2 mg) were added to cell suspensions of Synechococcus (turbidity at $720 \mathrm{~nm}$ was about 1.0; equivalent to $120-170 \mathrm{mg}$ wet-weight) in BG-11 medium $(20 \mathrm{~mL})$ at the beginning of the incubation period. The reaction mixture was shaken at $140 \mathrm{rpm}$ and $25^{\circ} \mathrm{C}$ under continuous illumination with a fluorescent lamp (daylight type, 0-53.6 $\mu \mathrm{mol}$ photons $\mathrm{m}^{-2} \cdot \mathrm{s}^{-1}$ ). Reaction times ranged from $12 \mathrm{~h}$ to $84 \mathrm{~h}$. The resulting mixture was extracted with ether and eluted from an Extrelut column (Merck, Darmstadt, Germany).

\section{Measurement of photosynthetic activity}

Photosynthetic $\mathrm{O}_{2}$ evolution of Synechococcus was measured with a Clark-type oxygen electrode (Model 4004; Yellow Springs Instruments, USA) (Murakami and Fujita 1988). An $\mathrm{O}_{2}$ electrode was placed in a plastic chamber (volume; ca $3 \mathrm{~mL}$ ) and maintained at $25 \pm 0.1^{\circ} \mathrm{C}$ with circulating thermostated water. The cell suspension of Synechococcus was stirred at a continuous speed with a magnetic stirrer. The rate of $\mathrm{O}_{2}$ evolution before and after the addition of DCMU (to final concentrations of $0,0.1,1,10$, or $100 \mu \mathrm{M}$ ) in DMSO (dimethyl sulfoxide) $(100 \mu \mathrm{L})$ was measured under illumination with a halogen lamp $\left(12.5 \mu \mathrm{mol}\right.$ photons $\left.\mathrm{m}^{-2} \cdot \mathrm{s}^{-1}\right)$. 
Assay for reduction of ketones with cell-free extracts Acetone-dried powder was used as cell-free extract. Cell suspension of Synechococcus (ca. $100 \mathrm{~mL}$ ) was centrifuged for $15 \mathrm{~min}$ at $8,000 \mathrm{rpm}$ and $4^{\circ} \mathrm{C}$. The precipitate was immediately treated with cold acetone $\left(-20^{\circ} \mathrm{C}\right)$ and dried under vacuum overnight, which gave $40 \mathrm{mg}$ of acetone-dried powder.

A reaction mixture $(2 \mathrm{~mL}$ of $0.1 \mathrm{M}$ potassium phosphate buffer, pH 7) containing $10 \mathrm{mg}$ acetone dried powder, $2 \mathrm{mg}$ substrate (TFA or PF), and $5 \mathrm{mg}$ reductant (NADPH or NADH) were incubated for $44 \mathrm{~h}$ at $25^{\circ} \mathrm{C}$ in the dark. The resulting mixture was extracted with ether and eluted with an Extrelut column.

\section{Results}

Light-dependency of the reduction of exogenous ketones by cyanobacterial cells

A time-course of the reduction of a ketone (TFA) by Synechococcus under continuous illumination $(13.4 \mu \mathrm{mol}$ photons $\mathrm{m}^{-2} \cdot \mathrm{s}^{-1}$ ) is shown in Figure 1 . The reaction proceeded gradually and upon saturation reached a plateau after about $60 \mathrm{~h}$. Therefore, the following experiments in this study were carried out with a 12 -h incubation period.

To investigate the dependency of light intensity on cyanobacterial ketone reduction in detail, the reduction activity was measured under varying light intensity $(0$, $2.7,6.7,13.4,33.5$, or $53.6 \mu \mathrm{mol}$ photons $\left.\mathrm{m}^{-2} \cdot \mathrm{s}^{-1}\right)$. As shown in Figure 2, the highest yield of TFA reduction was obtained in the reaction with $13.4 \mu \mathrm{mol}$ photons $\mathrm{m}^{-}$ ${ }^{2} \cdot \mathrm{s}^{-1}$. In the case of the reduction of PF, the maximal reduction activity was also obtained at the same light intensity (data not shown). This light intensity might be

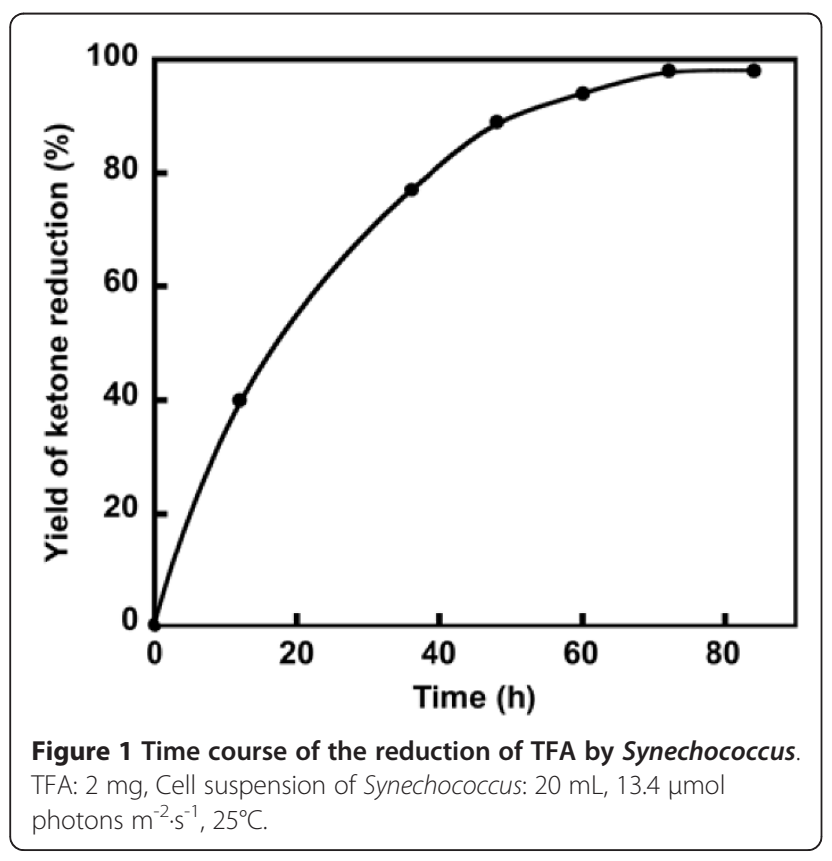

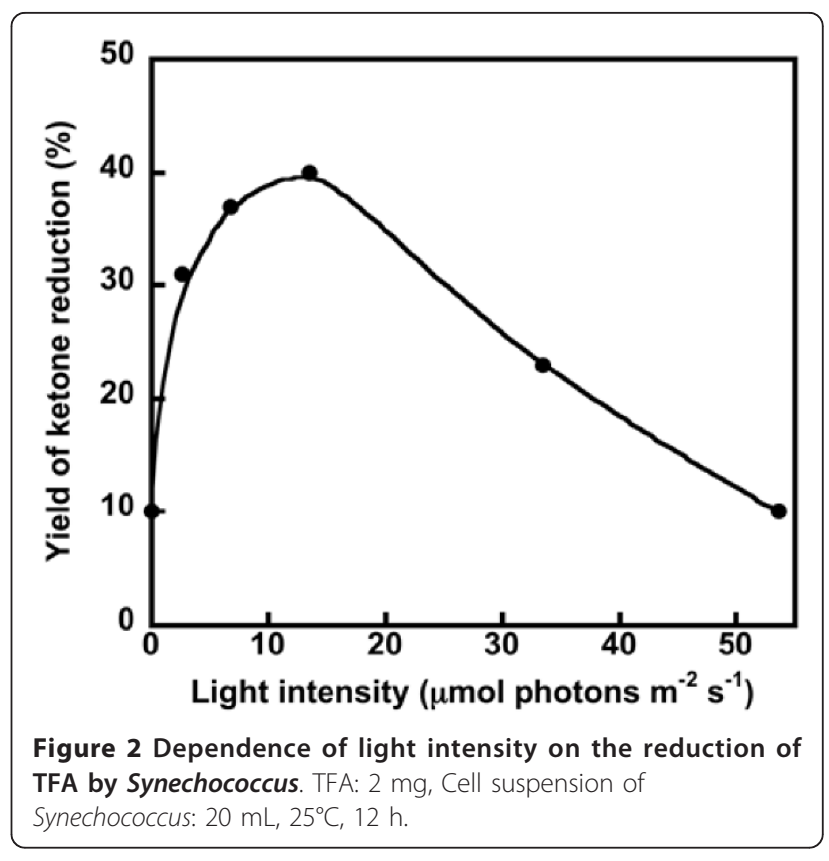

compatible with the optimal light intensity for growth of Synechococcus under our experimental conditions. The enantiomeric excess of the reduction of TFA was $85 \%(R)$ and was found to be independent of the light intensity.

\section{Suppression of cyanobacterial ketone reduction by} inhibition of photosynthetic electron transport

DCMU is a potent and specific inhibitor of photosynthetic electron transport (Fujita et al. 1987). TFA was incubated in an intact cell suspension of Synechococcus for $12 \mathrm{~h}$ under illumination $\left(13.4 \mu \mathrm{mol}\right.$ photons $\left.\mathrm{m}^{-2} \cdot \mathrm{s}^{-1}\right)$ with addition of DCMU $(0,0.1,1$, or $10 \mu \mathrm{M})$. Photosynthetic activity of Synechococcus was measured under the same light iintensity. The photosynthetic activity of Synechococcus was barely inhibited in the presence of $10 \mu \mathrm{M}$ of DCMU and ketone reduction was suppressed depending upon concentrations of DCMU (Table 1). On the other hand, ketone reduction in the dark was found to be independent of the DCMU concentration (data not

Table 1 Suppression of ketone reduction in Synechococcus by inhibition of photosynthetic electron transport

\begin{tabular}{ccc}
\hline $\begin{array}{c}\text { DCMU } \\
(\boldsymbol{\mu M})\end{array}$ & $\begin{array}{c}\text { Photosynthetic activity } \\
\text { (relative) }\end{array}$ & $\begin{array}{c}\text { Yield of ketone reduction } \\
(\%)\end{array}$ \\
\hline 0 & 1.0 & 43 \\
0.1 & 0.42 & 44 \\
1 & 0.16 & 36 \\
10 & 0.038 & 15 \\
\hline
\end{tabular}

TFA: $2 \mathrm{mg}$, Cell suspension of Synechococcus: $20 \mathrm{~mL}, 13.4 \mu \mathrm{mol}$ photons $\mathrm{m}^{-2} \cdot \mathrm{s}^{-}$ $1,25^{\circ} \mathrm{C}, 12 \mathrm{~h}$

DCMU was added at the beginning of the incubation period. 
shown). The results indicate that cyanobacterial reduction of exogenous ketone is closely associated with photosynthetic electron transfer activity.

\section{Ketone reduction depends upon photosynthetic activity} The current results suggest that ketone reduction is associated with photosynthetic activity. The relationship between yields of cyanobacterial TFA reduction and photosynthetic activity was investigated under varying light intensity or under different concentrations of DCMU. The data from Figure 2 and Table 1 are plotted together in Figure 3. Thus, the result shows that cyanobacterial ketone reduction depends upon the photosynthetic activity of the cyanobacteria.

\section{Enhancement of ketone reduction by suppression of NADPH consumption in the Calvin cycle}

In the reduction step of the Calvin cycle, a large amount of NADPH (6 equivalents of NADPH per cycle) generated photosynthetically was found to be consumed (Figure 4). Therefore, we used inhibitors of the Calvin cycle to examine the involvement of NADPH in cyanobacterial ketone reduction. Ribulose-1,5-bisphosphate carboxylase-oxygenase (RuBisCo) catalyzes the carboxylation step and ribulose-5-phosphate (Ru5P) kinase catalyzes the regeneration step, both of which are reactions of the Calvin cycle (Wirtz et al. 1982). These enzymes are inhibited by $\mathrm{SH}$-reagents such as iodoacetamide (IAM) or iodoacetic acid (IAA) (Figure 4). IAM or IAA (0.1 or $1 \mathrm{mM}$ ) was added in cell suspensions of Synechococcus with TFA under illumination. As shown in Table 2, IAM and IAA both enhance the reduction of TFA by Synechococcus (1.5-fold increase in the yield of reduction).

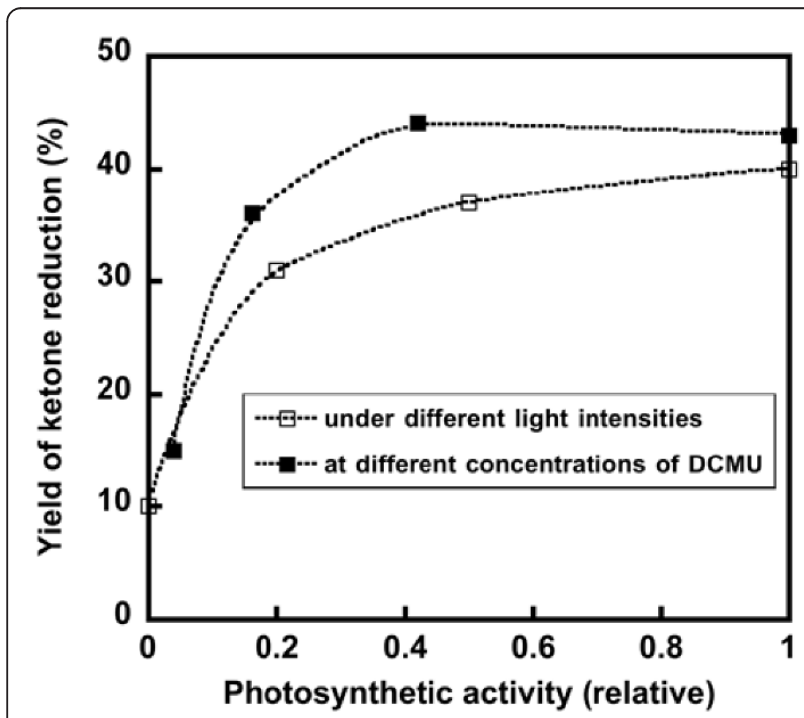

Figure 3 Correlation of photosynthetic activity and reduction of TFA. The data are from Table 1 and Figure 2.
Moreover, the effects of the inhibitors (D,L-glyceraldehyde and 5'-AMP) of phosphoribulose kinase or isomerase which are involved in the process of regeneration of $\mathrm{RuBp}$ (ribulose-1,5-bisphosphate) (Forsee and Kahn 1972, Slabas and Walker 1976) were investigated. As shown in Table 2, the yields of the reduction of TFA by the cyanobacterium were increased by the addition of D,L-glyceraldehyde or 5'-AMP (1.5-fold increase in the yield of reduction).

These results surely suggest that inhibition of the Calvin cycle increases the levels of NADPH, which can then be used to reduce an exogenous ketone.

\section{Ketone reduction by dark respiratory activity of cyanobacteria}

The TFA reduction by Synechococcus proceeded to some extent even in the dark (Figure 2) and DCMU did not completely suppress the reaction (Table 1 ). In cyanobacteria, the respiratory electron transport system is shared with the thylakoidal photosynthetic system and produces NADPH in the dark. Addition of DBMIB, an inhibitor of Cyt $b_{6}-f$, resulted in cessation of TFA reduction in the dark, although the chemical yield of ketone reduction without DBMIB was $16 \%$ (data not shown). These results suggest that the reducing power with respect to exogenous ketones is also supplied by the respiratory system, even though the supply of reductants is limited.

\section{Confirmation of coenzyme dependency on cyanobacterial} ketone reduction using a cell-free system

The current results suggest that endogenous reductase(s) is involved in cyanobacterial ketone reduction. To characterize the reductase(s), we investigated the ketone reduction activity of both the soluble and insoluble fractions. More than $95 \%$ of the reduction activity was detected in the soluble fraction (data not shown). This suggests that one or more hydrophilic enzymes participate in the artificial ketone reduction reaction. We confirmed the coenzyme (NADH/NADPH) dependency of the putative reductase(s) using the soluble fraction prepared from the cyanobacterium as an acetone-dried powder. It was found that NADPH is preferentially used in the reduction for both TFA and PF (Table 3). The results demonstrate that cyanobacterial ketone reduction is highly dependent on NADPH.

\section{Discussion}

In this study, we demonstrated that the reduction of exogenously added ketones in cyanobacterial cells is highly dependent upon photosynthetic activity (Figure 2 and Table 1). Similar correlation curves for the reduction activities of ketones and the photosynthetic activities of the cyanobacterium were obtained from two different modulation mechanisms of photosynthetic activity (Figure 3). Since cyanobacterial ketone reduction 


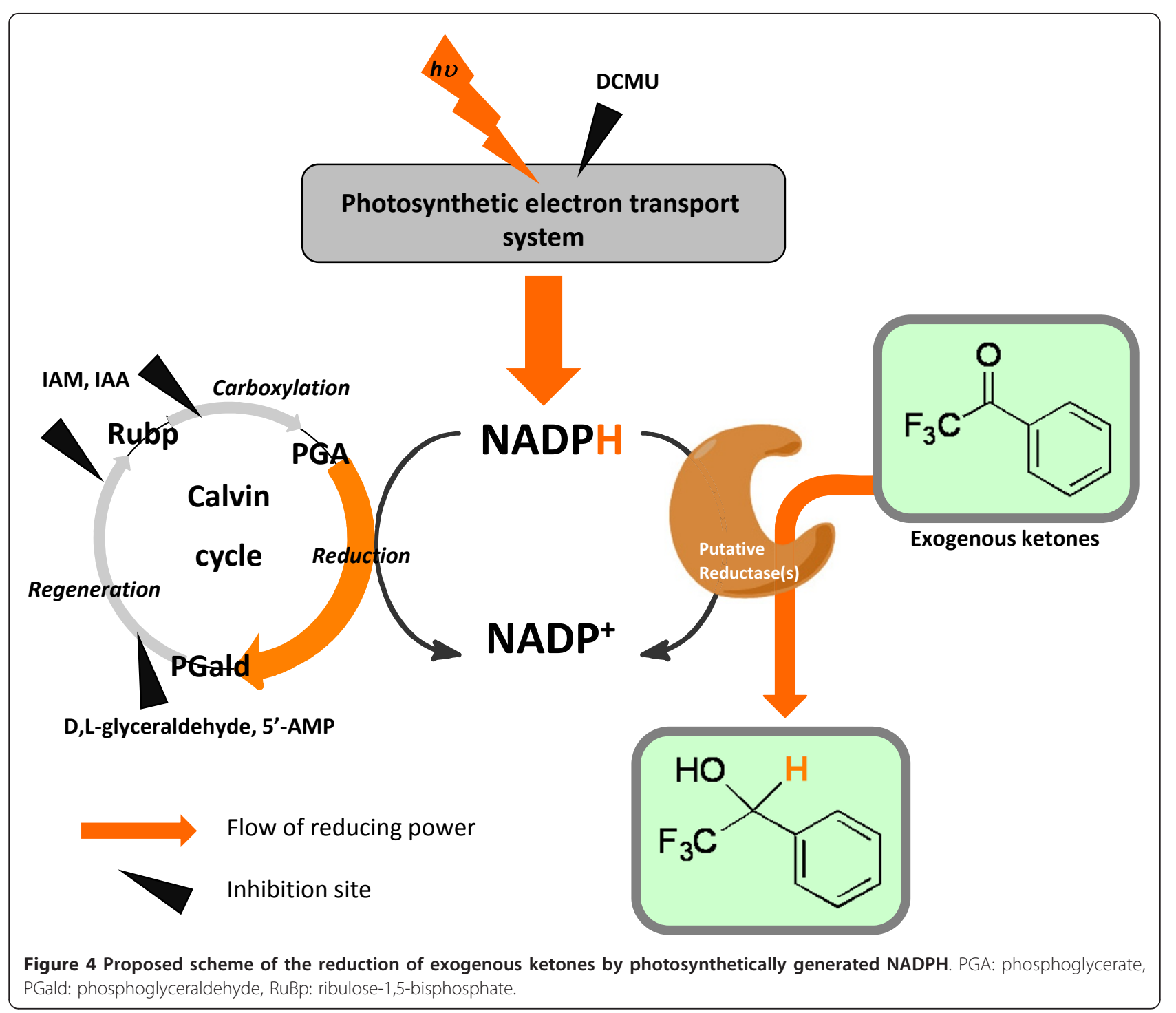

was expectedly found to be enhanced by inhibitors of the Calvin cycle (Table 2), we propose that the reducing power of NADPH generated through photosynthesis (which is primarily used in $\mathrm{CO}_{2}$ fixation), can also be used for the reduction of exogenous ketones to produce the corresponding alcohols.

Table 2 Enhancement of ketone reduction in Synechococcus by inhibition of the Calvin cycle

\begin{tabular}{cccc}
\hline & Inhibitor & Concentration (mM) & Yield of ketone reduction (\%) \\
\hline Experiment 1 & None & - & $34(1.00)^{*}$ \\
& IAM & 0.1 & $43(1.26)^{*}$ \\
& IAM & 1 & $52(1.53)^{*}$ \\
& IAA & 0.1 & $39(1.15)^{*}$ \\
\hline Experiment 2 & IAA & 1 & $61(1.49)^{*}$ \\
\hline & None & - & $40(1.00)^{*}$ \\
& D,L-glyceraldehyde & 10 & $57(1.43)^{*}$ \\
\hline
\end{tabular}

TFA: $2 \mathrm{mg}$, Cell suspension of Synechococcus: $20 \mathrm{~mL}, 13.4 \mu \mathrm{mol}$ photons $\mathrm{m}^{-2} \cdot \mathrm{s}^{-1}, 25^{\circ} \mathrm{C}, 12 \mathrm{~h}$

Inhibitors were added at the beginning of the incubation period.

*Values in parentheses are relative to the yield without inhibitor. 
Reduction of substrates usually requires large amounts of energy. For the majority of redox enzymes, NADH and its phosphorylated form NADPH are essential endogenous coenzymes (Nakamura and Matsuda, 2002). As shown in Table 3, we confirmed that the ketone reduction observed in the present study is mediated by NADPH coenzyme. Coenzymes are prohibitively expensive if used in stoichiometric amounts. Since it is only the oxidation state of the coenzyme that changes during the reaction and in the reduction of a ketone oxidized form of the coenzyme generated, it may be regenerated in situ by using a second redox-reaction to allow it to re-enter the reaction cycle. Usually, formate (Seelbach et al. 1996), glucose (Wong et al. 1985), ethanol (Lam et al. 1988) and 2-propanol (Matsuda et al. 2000) are used to regenerate the oxidized form to the reduced form. These coenzymes are originally derived from photosynthetic products. In Synechococcus, glucose has also been used as a supplier of NADPH for ketone reduction (Havel et al. 2007). The previous research is compatible with the present results in terms of using NADPH as a reductant. The addition of DCMU did not lead to complete inhibition of cyanobacterial ketone reduction. In fact, cyanobacteria generally produce NADPH mainly through the photosynthetic reaction. Secondary sources of NADPH include the pentose phosphate cycle system in respiration. NADH is additionally produced through glycolysis (Scherer et al. 1988) as the major reductant. Indeed, the addition of DBMIB, a respiratory inhibitor, was found to reduce cyanobacterial ketone reduction activity (data not shown).

As shown in Figure 2, the reduction activity under illuminated conditions was found to be 4-fold higher than the reduction activity in the dark. Tamoi et al. reported that the NADPH/NADH ratio under light conditions is higher than the reduction activity in the dark, although the difference is less than 4-fold in the cells of Synechococcus PCC 7942 (Tamoi et al. 2005). We previously reported that light conditions change the enantiomeric excess of the products of the cyanobacterial reduction (Nakamura and

\begin{tabular}{|c|c|c|}
\hline Substrate & Coenzyme & Yield of ketone reduction (\%) \\
\hline \multirow[t]{2}{*}{ TFA } & $\mathrm{NADPH}$ & $16(1.00)^{*}$ \\
\hline & $\mathrm{NADH}$ & $3.5(0.22)^{*}$ \\
\hline \multirow[t]{2}{*}{ PF } & $\mathrm{NADPH}$ & $12(1.00)^{*}$ \\
\hline & NADH & $0.8(0.07)^{*}$ \\
\hline
\end{tabular}

Substrate: $2 \mathrm{mg}, 0.1 \mathrm{M}$ potassium phosphate buffer ( $\mathrm{pH}$ ): $2 \mathrm{~mL}$, Acetone-dried powder of Synechococcus: $10 \mathrm{mg}, \mathrm{NADH}$ or NADPH: $5 \mathrm{mg}, 25^{\circ} \mathrm{C}$, $44 \mathrm{~h}$

*Values in parentheses are the relative to the yields in the presence of $\mathrm{NADPH}$.
Yamanaka, 2002b). In the ketone reduction reaction catalyzed by plant cultured-cells, different stereoselectivities have been obtained under light conditions with high $\mathrm{CO}_{2}$ concentrations and under dark condition with glucose (Kojima et al. 2009). Since the selectivity of the enzymatic reaction is fairly high in most cases, the low enantioselectivity usually means that a plurality of enzymes is involved in the reaction. In the present research, we have determined that light may increase the number of activated enzymes involved in the reduction in addition to increasing the concentration of NADPH. Hölsch et al. identified the enzymes involved in the cyanobacterial reduction reaction (Hölsch et al. 2008, Hölsch and Weuster-Botz, 2010). The reductases from Synechococcus PCC 7942 reduced acetophenone derivatives and may involve in our cyanobacterial ketone reduction. However, there may be some additional enzymes involved in the cyanobacterial TFA reduction because of the low enantioselectivity.

In summary, we have illustrated a possible mechanism for the reduction of exogenous ketones in cyanobacterial cells (see Figure 4). Exogenously-added ketones could be reduced by NADPH generated photosynthetically and NADPH is consumed in competition between the enzymes of the Calvin cycle and putative ketone reductases. Consequently, we have developed a new and useful application of cyanobacteria. The appropriation of NADPH generated by photosynthesis appears to contribute to a conversion mechanism for inexhaustible solar energy. The application of photosynthetic microalgae as biocatalysts using solar energy is expected to be developed in various efforts employing biotechnology, electrochemistry, and plant physiology (Abed et al. 2009). It is expected that photosynthetic microalgae will contribute to the development of many industrial synthetic reactions for production of useful compounds as well as efforts to design and optimize bioreactors (Walker et al. 2005) and to remediate environmental pollutants (Kuritz and Wolk 1995, Dubey SK et al. 2011).

\section{Abbreviations \\ DBMIB: 2,5-dibromo-3-methyl-6-isopropyl-p-benzoquinone (dibromothymoquinone); DCMU: 3-(3,4-dichlorophenyl)-1,1-dimethylurea; DMSO: dimethyl sulfoxide; GC: gas chromatography; IAA: iodoacetic acid; IAM: iodoacetamide; NAD(P)H: nicotinamide adenine dinucleotide (phosphate); PF: 2', 3', 4', 5', 6'-pentafluoroacetophenone; TFA: a, a, a- trifluoroacetophenone}

\section{Acknowledgements}

This research was supported in part by the Japanese Organic Synthetic Chemistry Organization Award for Research Planning (Sumitomo Chemical Co.) to R. Y. and a Grant-in-Aid for Scientific Research from JSPS (23370013) to A.M.

\section{Author details}

TFaculty of Pharmaceutical Science, Himeji-Dokkyo University, 7-2-1 KamiOhno, Himeji, Hyogo 670-8524, Japan ${ }^{2}$ Graduate School of Human Development and Environment, Kobe University, 3-11 Tsurukabuto, Nada-ku, Kobe, Hyogo 657-8501, Japan ${ }^{3}$ Kobe University Research Center for Inland Seas, 2746 Iwaya, Awaji, Hyogo 656-2401, Japan 


\section{Competing interests}

The authors declare that they have no competing interests.

Received: 17 August 2011 Accepted: 1 September 2011

Published: 1 September 2011

\section{References}

Abed RMM, Dobretsov S, Sudesh K (2009) Applications of cyanobacteria in biotechnology. J Appl Microbiol 106:1-12. doi:10.1111/j.13652672.2008.03918.x.

Anemaet IG, Bekker M, Hellingwerf KJ (2010) Algal photosynthesis as the primary driver for a sustainable development in energy, feed, and food production. Mar Biotechnol 12:619-629. doi:10.1007/s10126-010-9311-1.

Carey JS, Laffan D, Thomsonc C, Williamsd MT (2006) Analysis of the reactions used for the preparation of drug candidate molecules. Org Biomol Chem 4:2337-2347. doi:10.1039/b602413k.

Dubey SK, Dubey J, Mehra S, Tiwari P, Bishwas AJ (2011) Potential use of cyanobacteria species in bioremediation of industrial effluents. African J Biotechnol 10:1125-1132

Forsee WT, Kahn JS (1972) Carbon dioxide fixation by isolated chloroplasts of Egulena gracilis. II. Inhibition of $\mathrm{CO}_{2}$ fixation by AMP. Arch Biochem Biophys 150:302-309. doi:10.1016/0003-9861(72)90039-2.

Fujita Y, Murakami A, Ohki K (1987) Regulation of photosystem composition in the cyanobacterial photosynthetic system: the regulation occurs in response to the redox state of the electron pool located between the two photosystems. Plant Cell Physiol 28:283-292

Goldberg K, Schroer K, Lutz S, Liese A (2007) Biocatalytic ketone reduction - a powerful tool for the production of chiral alcohols - part 1: processes with isolated enzymes. Appl Microbial Biotechnol 76:237-248. doi:10.1007/s00253007-1002-0

Goldberg K, Schroer K, Lutz S, Liese A (2007) Biocatalytic ketone reduction - a powerful tool for the production of chiral alcohols - part 2: whole-cell reductions. Appl Microbial Biotechnol 76:249-255. doi:10.1007/s00253-007$1005-\mathrm{x}$.

Havel J, Weuster-Botz D (2007) Cofactor regeneration in phototrophic cyanobacteria applied for asymmetric reduction of ketones. Appl Microbiol Biotechnol 75:1031-1037. doi:10.1007/s00253-007-0910-3.

Hölsch K, Havel J, Haslbeck M, Weuster-Botz D (2008) Identification, cloning and characterization of a novel ketoreductase from the cyanobacterium Synechococcus sp. strain PCC 7942. Appl Environ Microbiol 74:6697-6702. doi:10.1128/AEM.00925-08.

Hölsch K, Weuster-Botz D (2010) New oxidoreductases from cyanobacteria: exploring nature's diversity. Enzyme and Microbial Technology 47:228-235. doi:10.1016/j.enzmictec.2010.06.006.

Huisman GW, Liang J, Krebber A (2010) Practical chiral alcohol manufacture using ketoreductases. Curr Opin in Chem Biol 14:122-129. doi:10.1016/j. cbpa.2009.12.003.

Itoh K, Sakamaki H, Nakamura K, Horiuchi CA (2005) Biocatalytic asymmetric reduction of 3-acetylisoxazoles. Tetrahedron Asymmetry 16:1403-1408. doi:10.1016/j.tetasy.2005.02.024

Kojima H, Okada A, Takeda S, Nakamura K (2009) Effect of carbon dioxide concentrations on asymmetric reduction of ketones with plant-cultured cells. Tetrahedron Lett 50:7079-7081. doi:10.1016/j.tetlet.2009.10.002.

Kumar A, Ergas S, Yuan X, Sahu A, Zang Q, Dewulf J, Malcata FX, Langenhove H (2010) Enhanced $\mathrm{CO}_{2}$ fixation and biofuel production via microalgae: recent developments and future directions. Trends in Biotechnol 28:371-380. doi:10.1016/j.tibtech.2010.04.004.

Kuramoto T, Iwamoto K, Izumi M, Kirihata M, Yoshizako F (1999) Asymmetric reduction of ethyl 2-methyl 3-oxobutanoate by Chlorella. Biosci Biotech Biochem 63:598-601. doi:10.1271/bbb.63.598.

Kurano N, Sasaki T, Miyachi S (1998) Carbon and dioxide and microalgae. In: Inui T (ed) Advances in Chemical Conversions for Mitigating Carbon Dioxide Studies in Surface Science and Catalysis 114, Elsevier Science B V, 55-63

Kuritz T, Wolk CP (1995) Use of filamentous cyanobacteria for biodegradation of organic pollutants. Appl Environmental Microbiol 61:234-238

Lam LKP, Gair IA, Jones JB (1988) Enzymes in organic synthesis. 42. Stereoselective horse liver alcohol dehydrogenase catalyzed reductions of heterocyclic bicyclic ketones. J Org Chem 53:1611-1615. doi:10.1021/ jo00243a004.

Matsuda T, Harada T, Nakajima N, Itoh T, Nakamura K (2000) Two classes of enzymes of opposite stereochemistry in an organism: One for fluorinated and another for nonfluorinated substrates. J Org Chem 65:157-163. doi:10.1021/jo991283k.

Matsuda T, Yamanaka R, Nakamura K (2009) Recent progress in biocatalysis for asymmetric oxidation and reduction. Tetrahedron Asymmetry 20:513-557. doi:10.1016/j.tetasy.2008.12.035.

Matsuo K, Kawabe S, Tokuda Y, Eguchi T, Yamanaka R, Nakamura K (2008) Asymmetric reduction of ketones with a germinated plant. Tetrahedron Asymmetry 19:157-159. doi:10.1016/j.tetasy.2007.12.015.

Moore JC, Pollard DJ, Kosjek B, Devine PN (2007) Advances in the enzymatic reduction of ketones. Acc Chem Res 40:1412-1419. doi:10.1021/ar700167a.

Murakami A, Fujita Y (1988) Steady state of photosynthesis in cyanobacterial photosynthetic systems before and after regulation of electron transport composition: Overall rate of photosynthesis and PSI/PS II composition. Plant Cell Physiol 29:305-311

Nakamura K (2007) Future directions in photosynthetic organisms-catalyzed reaction. In: Matsuda T (ed) Future directions in Biocatalysts, Elsevier Science B V, 51-58

Nakamura K, Matsuda T (2002) Enzyme-catalyzed reduction reactions. In: Drauz K, Waldmann $\mathrm{H}$ (eds) Enzyme Catalysis in Organic Synthesis, A Comprehensive Handbook, vol 32. Wiley-VCH Verlag GmbH, Weinheim, pp 991-1047

Nakamura K, Yamanaka R (2002) Light mediated cofactor recycling system in biocatalytic asymmetric reduction of ketones. Chem Comm 1782-1783

Nakamura K, Yamanaka R (2002) Light-mediated regulation of asymmetric reduction of ketones by a cyanobacterium. Tetrahedron Asymmetry 23:2529-2533

Nakamura K, Yamanaka R, Matsuda T, Harada T (2003) Recent developments in asymmetric reduction of ketones with biocatalysts. Tetrahedron Asymmetry 14:2659-2681. doi:10.1016/S0957-4166(03)00526-3.

Nakamura K, Yamanaka R, Tohi K, Hamada H (2000) Cyanobacterium-catalyzed asymmetric reduction of ketones. Tetrahedron Lett 41:6799-6802. doi:10.1016/50040-4039(00)01132-1.

Noma Y, Asakawa Y (1992) Enantio- and diastereo-selectivity in the biotransformation of carveols by Euglena gracilis Z. Phytochem 31:2009-2011. doi:10.1016/0031-9422(92)80350-N.

Rippka R (1988) Isolation and purification of cyanobacteria. In: Packer L, Glazer AN (eds) Methods Enzymol, vol 167. Cyanobacteria, Academic Press, San Diego, pp 3-27

Scherer S, Almon H, Boger P (1988) Interaction of photosynthesis, respiration and nitrogen fixation in cyanobacteria. Photosyn Res 15:95-114. doi:10.1007/ BF00035255.

Seelbach K, Riebel B, Hummel W, Kula MR, Tishkov VI, Egorov AM, Wandrey C, Kragl AU (1996) Novel, efficient regenerating method of NADPH using a new formate dehydrogenase. Tetrahedron Lett 37:1377-1380. doi:10.1016/00404039(96)00010-X.

Shimoda K, Hirata T (2000) Biotransformation of enones with biocatalysts - two enone reductases from Astasia longa. J Mol Cat B: Enzymatic 8:255-264. doi:10.1016/S1381-1177(99)00076-4.

Shimoda K, Kubota N, Hamada H, Yamane S, Hirata T (2004) Asymmetric transformation of enones with Synechococcus sp PCC 7942. Bull Chem Soc Jpn 77:2269-2272. doi:10.1246/bcsj.77.2269.

Slabas AR, Walker DA (1976) Inhibition of spinach phosphoribulokinase by DLglyceraldehyde. Biochem J 153:613-619

Takano H, Haruyama H, Nakamura N, Sode K, Burges JG, Manabe E, Hirano M, Matsunaga $\mathrm{T}$ (1992) $\mathrm{CO}_{2}$ removal by high-density culture of a marine cyanobacterium Synechococcus sp. using an improved photobioreactor employing light-diffusing optical fibers. Appl Biochem Biotech , 34/35: $449-458$

Takeda S, Ogata Y, Kojima H, Okada A, Uranishi Y, Nakamura K (2011) Arabidopsis thaliana: a novel biocatalyst for asymmetric reductions. Plant Biotech 28:77-82. doi:10.5511/plantbiotechnology.10.0927a.

Takemura T, Akiyama K, Umeno N, Tamai Y, Ohta H, Nakamura K (2009) Asymmetric reduction of a ketone by knockout mutants of a cyanobacterium. J Mol Cat B:Enzymatic 60:93-95. doi:10.1016/j. molcatb.2009.03.017.

Tamoi M, Miyazaki T, Fukamizo T, Shigeoka S (2005) The Calvin cycle in cyanobacteria is regulated by $C P 12$ via the $\operatorname{NAD}(H) / N A D P(H)$ ratio under light/dark conditions. The Plant J 42:504-513. doi:10.1111/j.1365313X.2005.02391.X.

Ugwu CU, Ogbonna JC, Tanaka H (2005) Light/dark cyclic movement of algal culture (Synechocyctis aquatilis) in outdoor inclined tubular photobioreactor equipped with static mixers for efficient production of biomass. Biotechnol Lett 27:75-78. doi:10.1007/s10529-004-6931-4. 
Utsukihara T, Chai W, Kato N, Nakamura K, Horiuchi CA (2004) Reduction of (+)and (-)-camphorquinones by cyanobacteria. J Mol Cat B:Enzymatic 31:19-24. doi:10.1016/j.molcatb.2004.06.002

Utsukihara T, Misumi O, Kato N, Kuroiwa T, Horiuchi CA (2006) Reduction of various ketones by red algae. Tetrahedron Asymmetry 17:1179-1185. doi:10.1016/j.tetasy.2006.04.007.

Walker TL, Purton S, Becker DK, Collet C (2005) Microalgae as bioreactors. Plant Cell Rep 24:629-641. doi:10.1007/s00299-005-0004-6.

Wirtz W, Stitt M, Heldt HW (1982) Light activation of Calvin cycle enzymes as measured in pea leaves. FEBS Lett 142:223-226. doi:10.1016/0014-5793(82) 80139-7.

Wong CH, Druckhammer DG, Sweers HM (1985) Enzymatic vs. fermentative synthesis: thermostable glucose dehydrogenase catalyzed regeneration of $\mathrm{NAD}(\mathrm{P}) \mathrm{H}$ for use in enzymatic synthesis. J Am Chem Soc 107:4028-4031. doi:10.1021/ja00299a044

Zabochnicka-świątek M (2010) Algae-feedstock of the future. Archivum Combustionis 30:225-236

doi:10.1186/2191-0855-1-24

Cite this article as: Yamanaka et al:: Reduction of exogenous ketones depends upon NADPH generated photosynthetically in cells of the cyanobacterium Synechococcus PCC 7942. AMB Express 2011 1:24.

\section{Submit your manuscript to a SpringerOpen ${ }^{\mathcal{O}}$ journal and benefit from:}

- Convenient online submission

- Rigorous peer review

- Immediate publication on acceptance

- Open access: articles freely available online

- High visibility within the field

- Retaining the copyright to your article

Submit your next manuscript at $\gg$ springeropen.com 